\title{
Adhesion Capacity of Bacillus thuringiensis Spores and its Relation with Biofilm Formation
}

\author{
Patricia Gomez de Leon ${ }^{1 *}$, Ibarra Jorge $E^{2}$, Bravo Alejandra ${ }^{3}$ and Karina Garcia-Gutierrez ${ }^{1}$ \\ ${ }^{1}$ Department of Public Health, National Autonomous University of Mexico, Mexico DF, Mexico \\ ${ }^{2}$ Department: Biotechnology and Biochemistry, Cinvestav-Unit Irapuato, Irapuato, Mexico \\ ${ }^{3}$ Biotechnology Institute, National Autonomous University of Mexico, Cuernavaca, Mexico
}

Received: May 08, 2015; Accepted: July 13, 2015; Published: July 25, 2015

*Corresponding author: Patricia Gomez de Leon, Department of Public Health, School of Medicine, UNAM. Pin: 04510, Mexico DF, Mexico, Tel: +55-562-32249; Email: patriciagomezdeleon@hotmail.com

\begin{abstract}
Spores of Bacillus thuringiensis (Bt), used as bioinsecticide, represent a potential contamination risk of the equipment used for food processing and could also induce potential gastrointestinal symptoms in special cases of susceptible individuals. The objective of this work was to explore the in vitro adhesion capacity of Bt spores and its relation to the ability to form biofilms. The adhering capacity of spores of 65 Bt strains was determined in stainless steel tubes, as well as their ability to form biofilms on polystyrene microplates. We analyzed the relation of these two features. All strains showed a variable adhering capacity to stainless steel, ranging from $0.04 \%$ to $1.21 \%$ of the initial spore load of $\sim 1.7 \times 10^{7} \mathrm{CFU} /$ $\mathrm{mL}$. The, $92.3 \%$ of the strains were able to form biofilms at $96 \mathrm{~h}$. Was observed that 23 strains showed high capacity, 19 moderate, and 18 low to form biofilms. Twenty two of the 65 strains showed the lowest levels for both parameters ( $\mathrm{r}$ $=0.46$ ). Our data suggest that the adhesion capacity does not necessarily predict either the capacity to form biofilms or their magnitude.
\end{abstract}

Keywords: Bacillus thuringiensis; Adhesion; Biofilms

\section{Introduction}

Among sporulated Gram-positive bacteria, several members of the Bacillus genus have been isolated in diverse environments of the production and processing industry of food for human consumption [1]. Of the cereus group species, B. anthracis and $B$. cereus are known pathogens in humans, whereas the entomopathogenic species $B$. thuringiensis $(\mathrm{Bt})$ that is used in the production of different bioinsecticides is considered safe for humans and mammals in general [2]. However, a potentially pathogenic effect for mammals is still possible [3,4,5]. For instance, the persistence of spores in some products can, in principle, induce contamination of the equipment used in their processing, as has been suggested for B. cereus [6]. Consequently, this situation can lead to gastrointestinal symptoms in individual having an attenuated immuneresponse [7].

It is known that Bt spores and those of other Bacillus species, presenting exosporium, have a higher hydrophobicity, conferring them a higher adhesive potential to diverse materials [8,9], such as those used in industrial food processing [1,10-13]. To this respect, there are several reports on the in vitro capacity of these bacteria to adhere to stainless steel laminae and/or synthetic polymers [14-18].

Bacterial adhesion to a surface is a two-phases process: in the first phase, planktonic bacteria are moved to a surface by the effect of physical forces such as Brownian motion, van der Waals attraction forces, gravitational forces, the effect of surface electrostatic charge and hydrophobic interactions; in the second phase of adhesion, molecular irreversible reactions between bacterial surface structures and substratum surfaces become predominant $[19,20]$. Adhesion is an essential stage for the formation and subsequent growth of biofilms [19,21,22].

Biofilms are defined as microbial communities embedded in a polymer layer or matrix adhered to an inert surface or substrate, or to living cells or tissues $[23,24]$. Several members of the Bacillus genus are capable of forming biofilms in vitro at variable magnitudes dependent on the incubation time $[6,25]$. According to Auger et al. [25], less than $50 \%$ of the B. cereus and Bt strains showed capacity to form biofilm in their assays. Formation of biofilms has been related also to the resistance of these species to diverse antibiotics and disinfectants $[26,27]$ found that the latent spores of $B$. cereus were more efficient in starting and forming biofilms as compared to bacterial cells in vegetative or sessile state. These same authors evidenced that the production of biofilm in cultures with spores depends on the growth curves, which does not occur in cultures in suspension, and could be related to the resistance of the biofilm to adverse factors.

Despite the existence of important collections of Bt isolated from different regions of Mexico, few studies have focused on the possible associations and distribution of features that could contribute to the analysis and a better understanding of the relations at the level of species and subspecies of the very 
variable lineages of the Bacillus genus. Considering that diversity (or clonality) evidence can be obtained through several types of markers and that the correlation among results from different methodologies allows resolving doubts and clarify scenarios, we used both biofilm formation and adherence assessments in our study.

Based on the close genetic relation of Bt with the other members of the cereus group and, hence, their shared phenotypical characteristics [28], the present study was performed to explore the adhesion capacity of Bt spores to stainless steel tubes and its possible relation with the capacity to form biofilms on polystyrene plates.

\section{Methods}

\section{Bacteria and cultures}

We studied a group of 63 strains of B. thuringiensis of environmental origin isolated from diverse sources (Table 1).

Table 1: Characteristics of Bacillus thuringiensis strains analyzed in this study.

\begin{tabular}{|c|c|c|c|c|c|c|c|}
\hline Strain ${ }^{a}$ & Source $^{b}$ & Location $^{c}$ & Date $^{d}$ & Strain ${ }^{a}$ & Source $^{b}$ & Location $^{c}$ & Date $^{d}$ \\
\hline BT8 & CL & MX & Apr-89 & IB72 & CO & OAX & Aug-91 \\
\hline BT10 & CL & GTO & Jun-89 & IB74 & AS & OAX & Aug-91 \\
\hline BT11 & AS & GTO & Jun-89 & IB76 & $\mathrm{CO}$ & OAX & Aug-91 \\
\hline BT14 & CL & GTO & Jun-89 & IB80 & GR & MOR & Jun-91 \\
\hline BT20 & AS & GTO & Jun-89 & IB82 & $\mathrm{CO}$ & ZAC & Jun-91 \\
\hline BT21 & AS & GTO & Jun-89 & IB85 & AS & OAX & Aug-91 \\
\hline BT22 & AS & GTO & Jun-89 & IB86 & SC & OAX & Aug-91 \\
\hline BT23 & CL & GTO & Jun-89 & IB88 & AS & GTO & Jun-91/ \\
\hline BT25 & CL & GTO & Jun-89 & IB90 & SC & GTO & Jun-91 \\
\hline BT26 & $\mathrm{CO}$ & GTO & Jun-89 & IB91 & GR & GTO & Jun-91 \\
\hline BT28 & $\mathrm{CO}$ & GTO & Jun-89 & IB94 & GR & GTO & Jun-91 \\
\hline ВT34 & CO & GTO & Jun-89 & IB97 & GR & GTO & Aug-91 \\
\hline ВT35 & $\mathrm{CO}$ & GTO & Jun-89 & IB100 & GR & GTO & Jun-91 \\
\hline ВT36 & CO & QRO & Jun-89 & IB115 & CO & TAB & Aug-91 \\
\hline ВT38 & $\mathrm{CO}$ & GTO & Jun-89 & IB120 & CO & TAB & Aug-91 \\
\hline IB4 & $\mathrm{CO}$ & MOR & Jun-91 & IB126 & $\mathrm{CO}$ & OAX & Aug-91 \\
\hline IB8 & GR & MOR & Jun-91 & IB130 & GR & TAB & Aug-91 \\
\hline IB9 & $\mathrm{CO}$ & MOR & Jun-91 & IB135 & GR & TAB & Aug-91 \\
\hline IB10 & AS & MOR & Jun-91 & IB136 & CO & TAB & Aug-91 \\
\hline IB13 & CO & PUE & Jun-91 & IB152 & AS & GTO & Jun-91 \\
\hline IB18 & AS & MOR & Jun-91 & IB155 & CO & OAX & Aug-91 \\
\hline IB19 & $\mathrm{CO}$ & OAX & Aug-91 & IB157 & AS & TAB & Aug-91 \\
\hline IB23 & $\mathrm{CO}$ & PUE & Jun-91 & IB162 & $\mathrm{CO}$ & TAB & Aug-91 \\
\hline IB28 & $\mathrm{CO}$ & MOR & Jun-91 & IB163 & $\mathrm{CO}$ & OAX & Aug-91 \\
\hline IB29 & SC & GTO & Jun-91 & IB164 & AS & CHI & Aug-91 \\
\hline IB31 & GR & MOR & Jun-91 & IB177 & CO & TAB & Aug-91 \\
\hline IB33 & CO & MOR & Jun-91 & IB182 & CO & TAB & Aug-91 \\
\hline IB35 & GR & MOR & Jun-91 & IB189 & CO & CHI & Aug-91 \\
\hline IB42 & AS & MOR & Jun-91 & IB195 & AS & TAB & Aug-91 \\
\hline IB43 & SC & MOR & Jun-91 & IB213 & $\mathrm{CO}$ & PUE & Jun-91 \\
\hline IB52 & SC & MOR & Aug-91 & IB214 & AS & TAB & Aug-91 \\
\hline IB57 & SC & MOR & Jun-91 & & & & \\
\hline \multicolumn{8}{|c|}{$\begin{array}{l}\text { aBT strains from CINVESTAV Irapuato, and IB strains from Institute of Biotechnology, UNAM } \\
\text { bIsolated from: CL, crops leftover; AS, agricultural soil; CO, corn; Gr, grass; SC, sugar cane } \\
\text { 'Location (Mexican States): MX, State of Mexico; GTO, Guanajuato; QRO, Queretaro; MOR, Morelos;PUE, Puebla; OAX, Oaxaca; ZAC, Zacatecas; TAB, } \\
\text { Tabasco; CHI, Chiapas. } \\
\text { dCollecting date }\end{array}$} \\
\hline
\end{tabular}


We included the reference strains 10792 and 33679 (H3: 3a, $3 \mathrm{~b}$ ) of the ATCC (American Type Culture Collection).Fifteen of the studied strains were kindly donated by the Bioinsecticides Laboratory of the Department of Biotechnology and Biochemistry, from CINVESTAV-Irapuato, in Guanajuato, Mexico, and 48 were provided by the Department of Molecular Microbiology, from the Institute of Biotechnology-UNAM Cuernavaca, in Morelos, Mexico.

Strains were received desiccated in sterile filter paper; they were rehydrated in Soy Trypticase Broth (STB, Bioxon) and incubated at $30^{\circ} \mathrm{C}$ for 7 days. Strains were individually harvested in sterile cryovials containing STB supplemented with $2 \%$ fat-free milk (Difco) plus $15 \%$ glycerol (JT Baker), and stored at $-70^{\circ} \mathrm{C}$.

To prepare the working solutions, loops of each frozen stock were re-sown directly on $1.5 \%$ Trypticase Soy Agar (TSA) plates, streaked, and incubated at $30^{\circ} \mathrm{C}$ for 7 days. They were immediately harvested individually in polystyrene tubes containing $3 \mathrm{ml}$ of sterile water with $0.1 \%$ Tween-80, and kept refrigerated until used.

\section{Spores adhesion}

The method described by Wijman et al. [6] with some modifications was used. Briefly, fresh spore suspensions were prepared in $10 \mathrm{mM}$ potassium phosphate buffer (pH 7.4) with $0.1 \%$ Tween 80 , adjusted to an $\mathrm{OD}_{545}$ of 0.3 , and immediately $2 \mathrm{ml}$ aliquots of each standardized suspension were placed in sensitized stainless steel tubes with ultra pasteurized fat-free milk ( 4 replicates). Then, $20 \mu \mathrm{L}$ aliquots were taken from each tube to make serial decimal dilutions with STB on microplates, and plated on TSA with $2 \%$ agar ( $2 \%$ TSA). Tubes were closed with rubber sterile stoppers and incubated at $30^{\circ} \mathrm{C}$ for $4 \mathrm{~h}$ under agitation at $60 \mathrm{rpm}$. Supernatants were discarded; tubes were rinsed three times under aseptic conditions with sterile deionized water. Immediately, $2 \mathrm{~mL}$ of $10 \mathrm{mM}$ sodium phosphate buffer $\mathrm{pH}$ 7.4) with $0.5 \%$ Tween 80 were added to the tubes, and placed in an ultrasonic bath (Branson 2800) at $40 \mathrm{kHz}$ for $10 \mathrm{~min}$ at room temperature; the tubes were placed into an ice bath. The resulting spore suspensions were serially diluted in STB and plated in $2 \%$ TSA. Both the microplate and the $2 \%$ TSA preparations were incubated at $30^{\circ} \mathrm{C}$ during the night. Finally, strain colonies were counted per plate/dilution. These experiments were done in duplicate.

\section{Biofilms formation}

We followed the methodology proposed by Wijman, et al. [6] and Stepanovic, et al. [24] with minor modifications García, et al. [29]. Spore suspensions were standardized at an $\mathrm{OD}_{545}$ of 0.6 with STB and immediately $200 \mu \mathrm{L}$ aliquots of each strain suspension were placed in series of 12 adjacent wells in 96-well microtiter polystyrene plates, and incubated at $30^{\circ} \mathrm{C}$ during $96 \mathrm{~h}$. A series of wells with STB was included as control in each plate.

After incubation, supernatants were removed by mild aspiration with a vacuum pump; microplates were washed with $220 \mu \mathrm{L} /$ well of $1 \mathrm{X}$ phosphate buffered saline (PBS), fixed with 220 $\mu \mathrm{L} /$ well of $100 \%$ methanol during $5 \mathrm{~min}$ at room temperature
(RT); stained with $220 \mu \mathrm{L}$ of $1 \%$ crystal violet per well for $15 \mathrm{~min}$ at RT, rinsed twice with $220 \mu \mathrm{L} /$ well of sterile distilled water and air dried at RT. Finally, the crystal violet retained in the biofilms was solubilized with $220 \mu \mathrm{L} /$ well of $33 \%$ glacial acetic acid and $\mathrm{OD}_{620}$ readings were made in an automated microplate reader (Multiskan Ex, Thermo Electron).

\section{Data analysis}

Counts of colonies from the adhesion assay were used to calculate the average of colony forming units per milliliter (CFU/ $\mathrm{mL}$ ) at the start and end of the assay.

Mean $\mathrm{OD}_{620}$ values from replicates were calculated for all strains and controls at each time of incubation. The mean $\mathrm{OD}_{620}$ values were considered acceptable if their corresponding coefficients of variation (CVs) were less than $20 \%$. The mean $\mathrm{OD}_{620}$ value of controls was used to set three cut-off values according to Stepanovic, et al. [24], and subsequently to categorize the bacteria, as Null-, Weak-, Moderate-, or Strong-Biofilm forming strains.

Statistical analyses of data were performed by means of parametric and/or non-parametric tests, as required, with the Software SPSS statistics v. 20 (IBM Corp.)

Pearson product-moment correlation coefficient was calculated.

\section{Results}

\section{Adhesion capacity}

Of all the strains, $26.2 \%(17 / 65)$ reached adhesion values below $0.2 \%$; $33.8 \%(22 / 65)$ showed adhesion values $\geq 0.2$ and $<0.5 \%$; whereas $32.3 \%(21 / 65)$ showed values $\geq 0.5$ and $<1.0 \%$. Only five strains $(7.7 \%)$ showed adhesion values $<0.3 \%$. All strains analyzed revealed adhering capacity to stainless steel in the presence of fat-free milk, but at a variable magnitude. In average (1.15-2.11 CFU), the initial load of spores in the tubes was of $1.68 \times 10^{7} \mathrm{CFU} / \mathrm{mL}$, whereas the average (3.55-5.83 CFU) of adhered spores was $4.7 \times 10^{4} \mathrm{CFU} / \mathrm{mL}$, representing a difference of approximately $2.5 \log _{10}$ units. These data indicated that the percentages of adhering spores were below $1.5 \%$ of the initial loads and showed a large variability, ranging from $0.04 \%$ to $1.21 \%$. The total distribution of the adhesion percentages is shown in Figure 1.

No significant difference was observed in the average values of adhesion percentage between the CINVESTAV-Irapuato strains (strains BT) and those of the Institute of Biotechnology-UNAM (strains IB). The strains of each institution showed adhesion percentage values that were heterogeneously distributed in the range of values.

\section{Biofilms}

Under the used experimental conditions, biofilms were formed as rings of adherent material in the air-liquid interface of the wells of the microplate, with variable thickness and density. Sixty out of the 65 strains $(92.3 \%)$ showed variable capacity to form biofilms at $96 \mathrm{~h}$ of incubation with an $\mathrm{OD}_{620}$ range of 0.27 to 3.59 (Figure 2). 


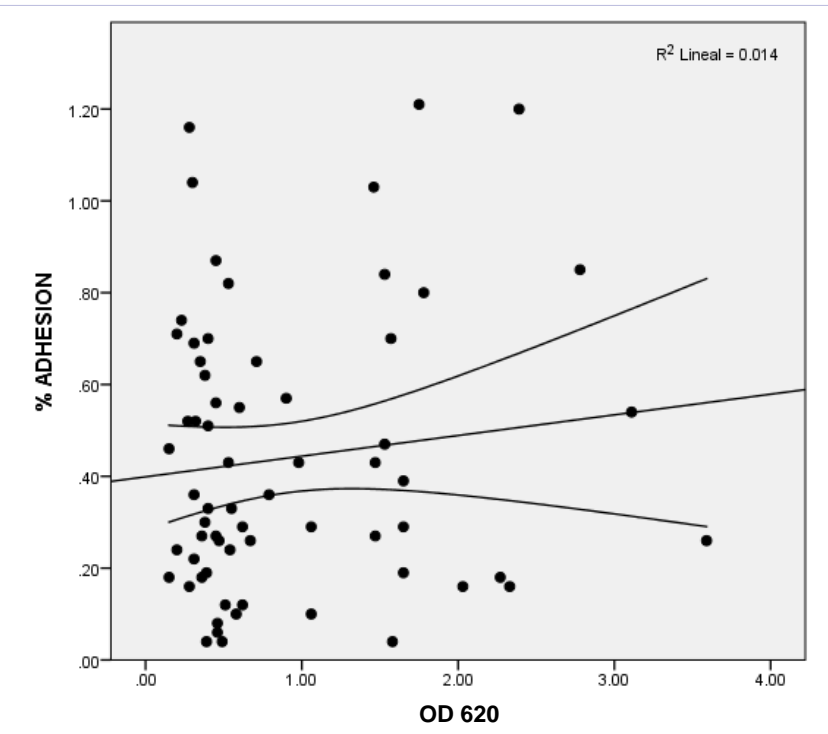

Figure 1: Distribution of the adhesion percentages with respect to the OD620 according to the capacity to form biofilms of the $65 \mathrm{Bt}$ strains. The insert shows the pattern of aggregated distribution of the subpopulation that presented low values for both parameters.

According to the defined categories of biofilms formation, $35.4 \%, 29.2 \%, 27.7 \%$, and $7.7 \%$ of the strains revealed high, moderate, low, and null capacity, respectively. The distribution of the capacity to form biofilms between the BT and IB strains was similar $(\mathrm{P}<0.05)$.

The two reference strains included in the study showed dissimilar capacities to form biofilms: strain ATCC 10792 was highly producing $\left(\mathrm{OD}_{620}=3.59\right)$ and strain ATCC 33679 was a moderate producer $\left(\mathrm{OD}_{620}=0.51\right)$.

Regarding the possible correlation between adherence and the capacity to form biofilms, the Person product-moment correlation coefficient for the whole data set of 63 strains was $r=$ 0.12 (negligible relationship). However, the subset data of strains showing an aggregated distribution pattern (Figure 1) for the lower levels of both adherence and capacity of forming biofilms showed a moderate correlation value of $r=0.46$.

\section{Discussion}

There are several reports on the capacity of diverse members of the Bacillus genus, particularly B. cereus and B. subtilis, to form biofilms in in vitro models [6,27]. Bacterial adhesion to a surface is an essential step for the formation of biofilms [19].

Although the information on the role of biofilms formation by the entomopathogenic Bt species in nature is scarce, it could be considered to be a potential resistance and persistence mechanism in susceptible insects [25].

The widespread use of spores with their toxic insecticide proteins (Cry or Cyt) as bioinsecticides to control relevant insect pests for agricultural crops [30] also implies a potential contamination source in the industrial processing and packaging lines of some agricultural products $[11,31]$.
In this study, we determined the adherent capacity of $B$. thuringiensis spores to stainless steel tubes, as an indicator of the Bt spores potential to persist adhered in industrial environments involved in the processing of vegetal origin food.

Our results indicate that Bt spores adhere to stainless steel surfaces at magnitudes that could be considered low with respect to the initial load in the order of 2 to 3 logarithms. The modified method used herein was useful to distinguish the adhering capacities of the studied Bt populations. These results agree with

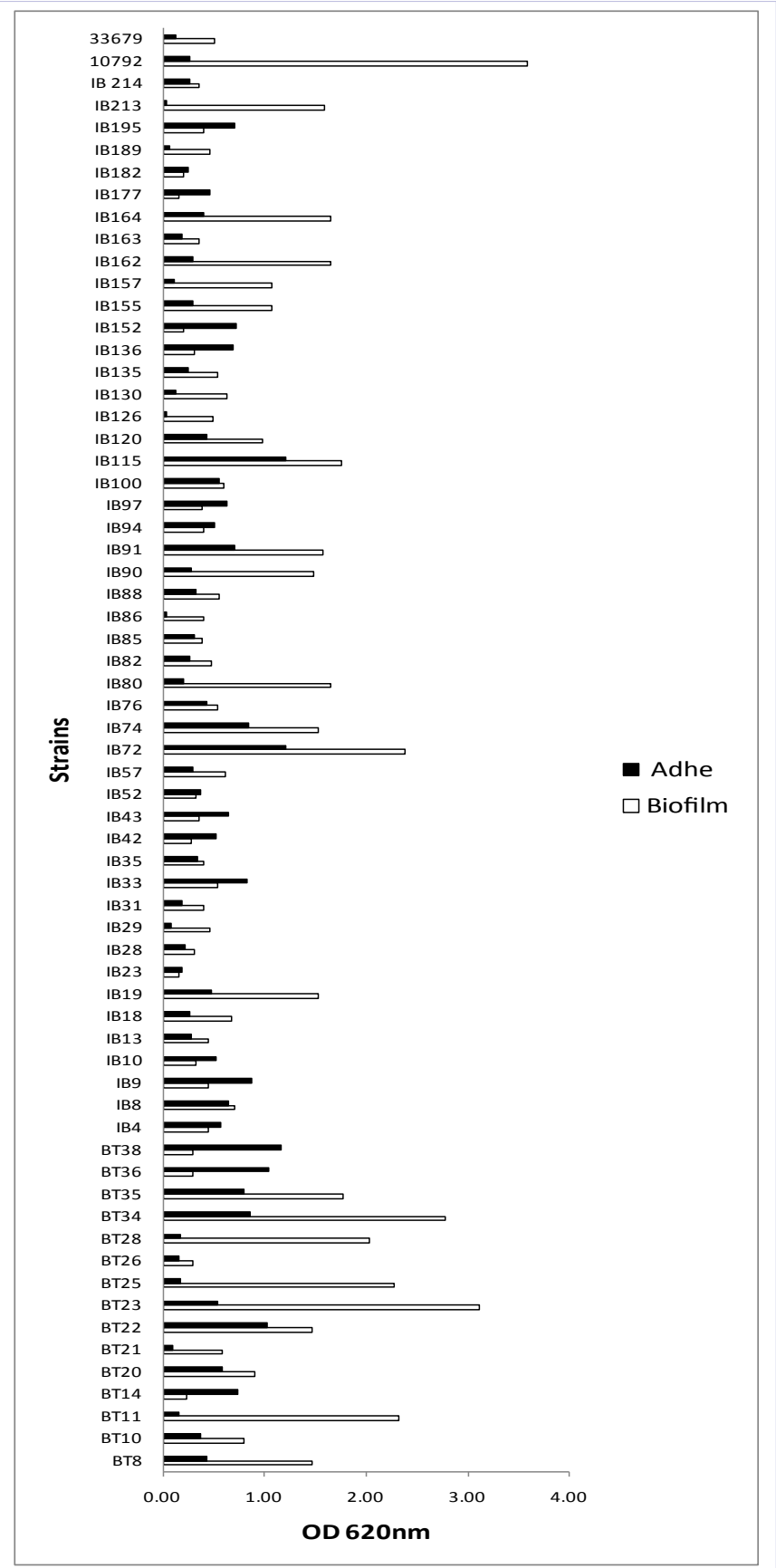

Figure 2: Distribution of the capacities to form biofilms at $96 \mathrm{~h}$ and adherence at $4 \mathrm{~h}$ by the Bt strains. 


\section{those of [6] for B. cereus regarding its adherence capacity.}

In the adhesion model used in this study, it is assumed that only the reversible adhesion of Bt spores was fostered, since an ionic regulator without carbon sources was used and the contact time was relatively short. We selected to use the Bt spores suspension to perform both the adhesion and the biofilms formation assays in this work based on the findings [27], as they observed a greater efficiency in adhesion and biofilms formation of $B$. cereus spores, in contrast to planktonic and/or sessile cells. Besides, they also observed that the sporulated phase of growth presents a more prolonged lag phase in the growth curve in biofilms than in suspension, which could have implications in the resistance of biofilms to stressing factors.

The capacity of the Bt strains to form biofilms in this study was heterogeneous, their categorizing practically showed similar proportions of high, moderate, and low producing strains. Such a distribution had already been observed in a smaller group of strains [29]. Other studies with different Bacillus species have also shown variable capacities to form biofilms in vitro [6,25,32] It is important to point out that more than $90 \%$ of the studied Bt strains were able to form biofilms. This could represent a contamination risk in the processing plants of agricultural products exposed to Bt-based bioinsecticides regardless of the innocuity of the bacterium.

The whole group of strains studied here showed full diversity richness. The subgroup from the CINVESTAV (BT) collection revealed greater diversity than that from the IBT-UNAM collection. This could be related to the fact that the CINVESTAV strains were isolated from neighboring localities; thus, it is more likely that genetic transfer and recombination among strains could have occurred [28].

Under our experimental conditions, incubation for $96 \mathrm{~h}$ at $30^{\circ} \mathrm{C}$ was optimal for the formation of biofilms by most $\mathrm{Bt}$ strains, coinciding with the late stationary growth phase. These data agree with the more efficient biofilms formation by B. cereus strains during nutrients depletion, generally in the transition from the exponential phase to the early stationary phase [33-35].

Our results suggest that other events different from those analyzed herein, such as genotypical and phenotypical switching, could be playing a significant role in the formation and differentiation of the biofilm.

Results obtained by Verplaetse, et al. [36], agree with our in terms of a high level of heterogeneity. These authors suggest that, in biofilm, the activity of three regulators is concomitant and happens in different subpopulations at the same time.

B. thuringiensis is ubicuitous in the soil even in extreme latitudes; however, there is no explanation for this. Very few investigations of microbial ecology have been carried out related to soil survival. To achieve this, we would have to widen the knowledge of our Bt subset obtained from the soil, by identifying the genes required by $\mathrm{Bt}$, such as the trasporter BMB171-C0350 [37].

The signal(s) that trigger the change from planktonic growth to biofilms are still unknown; but, there is a consensus that formation of biofilms is fostered in conditions of environmental stress and nutrients deficiency $[27,36,38]$.

On the other side, the initial adhesion of spores and subsequent formation of biofilms correlate with the production of high percentages of spores during the biofilm formation cycle [27]. The aforementioned can impact negatively the food processing industry, given the constant release of spores from the biofilm and their dissemination to form new biofilms.

Furthermore, Thomas et al. [39] established that the microorganisms isolated from any niche, such as medical, environmental, aquatic, or industrial, can exert different adhesion mechanisms, not only due to the variations in substrate, nutrients, ionic strengths, $\mathrm{pH}$ values, and temperature, but also because the phenotype and genotype (expression of structural components and adhesion proteins to surfaces) of the bacteria have undergone different adaptation processes along time through selective pressures.

In conclusion, we suggest taking into account the adhesion capacities and biofilms production, as reported here, for the routine phenotypical characterization of Bt populations. A moderate correlation between the capacity for biofilm formation and adherence was observed in the subset with the lowest values for both parameters. More studies should be done correlating these parameters among populations of strains of environmental origin and strains associated to contamination of the equipment used in the processing of some food products.

\section{Acknowledgement}

Two grants from Dirección General de Asuntos Académicos, Universidad Nacional Autónoma de México (DGAPA-UNAM) through its Programa PAPIIT (No. IN208410-3 and IN214414) and one from CONACYT (No. 117943M) supported this study.

Dr. Karina García-Gutiérrez is recipient of a fellowship from the Programa Posdoctoral DGAPA-UNAM. We thank Javier Díaz García and Dafne Gutiérrez for their participation in managing adherence methods. We thank also the excellent technical support from Liliana Hernández, Jorge Sanchez, and Regina Basurto. The authors also thank Ingrid Mascher for editorial assistance and for reviewing the proper usage of English in this manuscript.

\section{References}

1. Tauveron G, Slomianny C, Henry C, Faille C. Variability among Bacillus cereus strains in spore surface properties and influence on their ability to contaminate food surface equipment. Inter J Food Microbiol. 2006; $110(3): 254-62$.

2. Siegel JP, Shadduck JA, Szabo J. Safety of the entomopathogen Bacillus thuringiensis var. israelensis for mammals. J Econ Entomol. 1987; $80(4): 717-23$.

3. Noble MA, Riben PD, Cook GJ. Microbial and epidemiological surveillance program to monitor the health effects of Foray 48B BTK Spray. The Ministry of Forests. Vancouver: 1992.

4. Samples JR., Buettner H. Ocular infection caused by a biological insecticide. J. Infect. Dis. 1983; 148(3):614. 
5. Jackson SG, Goodbrand RB, Ahmed R, Kasatiya S. Bacillus cereus and Bacillus thuringiensis isolated in a gastroenteritis outbreak investigation. Lett Appl Microbiol. 1995; 21(2):103-5.

6. Wijman JG, de Leeuw PP, Moezelaar R, Zwietering MH, Abee T. Airliquid interface biofilms or Bacillus cereus: formation, sporulation and dispersion. Appl Environ Microbiol. 2007; 73(5):1481-8. doi:10.1128/ AEM.01781-06.

7. Green M, Heumann M, Sokolow R, Foster LR, Bryant R, Skeels M. Public health implications of the microbial pesticide Bacillus thuringiensis: an epidemiological study, Oregon, 1985-86. Am J Public Health. 1990; 80(7):848-52.

8. Henriques AO, Moran CP Jr. Structure, assembly, and function of the spore surface layers. Annu Rev Microbiol. 2007; 61:555-88. doi:10.1146/annurev.micro.61.08.0706.093224.

9. M C van Loosdrecht, J Lyklema, W Norde, G Schraa, A J Zehnder. The role of bacterial cell wall hydrophobicity in adhesion. Appl Environ Microbiol. 1987; 53(8):1893-1897.

10. Faille C, Fontaine F, Bénézech T. Potential occurrence of adhering living Bacillus spores in milk product processing lines. J Appl Microbiol. 2001; 90(6):892-900.

11. Faille C, Jullien C, Fontaine F, Bellon-Fontaine MN, Slomianny C, Benezech T. Adhesion of Bacillus spores and Escherichia coli cells to inert surfaces: role of surface hydrophobicity. Can J Microbiol. 2002; 48(8):728-38.

12. Lelievre C, Faille C, Benezech T. Removal kinetics of Bacillus cereus spores from stainless steel pipes under CIP procedure: Influence of soiling and cleaning conditions. J Food Process Eng. 2001; 24(6):359379. doi: 10.1111/j.1745-4530.2001.tb00549.x.

13. Peng JS, Tsai WC, Chou CC. Surface characteristics of Bacillus cereus and its adhesion to stainless steel. Int J Food Microbiol. 2001; 65(12):105-11.

14. Czechowski, M.H. Bacterial attachment to Buna-N gaskets in milk processing equipment. Aust J Dairy Technol. 1990; 45:113-114.

15. J. T. Holah. Industrial monitoring: hygiene in food processing. In: LF Melo, TR Bott, M Fletcher, B Capdeville editors. Biofilms-science and technology. Dordrecht: Kluwer Academic Publishers; 1992. p. 645659.

16. Krysinki E P, Brown L J, Marchisello T J. Effect of cleaners and sanitizers on Listeria monocytogenes attached to product contact surfaces. J Food Prot. 1992; 55(4):246-251(6).

17. Mafu A A, Roy D, Goulet J, Magny P. Attachment of Listeria monocytogenesto stainless steel, glass, polypropylene and rubber surfaces after short contact times. J Food Prot. 1990; 53(9):742-746.

18. Suárez B, Ferreirós CM, Criado MT. Adherence of psychrotropic bacteria to dairy equipment surfaces. J Dairy Res. 1992; 59(3):381-8.

19. An YH, Friedman RJ. Concise review of mechanisms of bacterial adhesion to biomaterial surfaces. J Biomed Mater Res. 1998; 43(3):338-48.

20.Garrett T R, Bhakko M, Zhang, Z. Bacterial adhesion and biofilms on surfaces. Progress in Natural Science.2008; 18(9):1049-1056. doi:10.1016/j.pnsc.2008.04.001.

21. K. C. Marshall, Ruby stout, R Mitchell. Mechanism of the initial events in the sorption of marine bacteria to surfaces. J Gen Microbiol. 1971; 68:337-348. doi: 10.1099/00221287-68-3-337.

22.E. A. Zottola. Characterization of the attachment matrix of Pseudomonas fragi attached to non-porous surfaces. Biofouling: The Journal of Bioadhesion and Biofilm Research. 1991; 5(1-2):37-55.
23. Kumar CG, Anand SK. Significance of microbial biofilms in food industry: a review. Int J Food Microbiol. 1998; 42 (1-2):9-27. doi:10.1016/S0168-1605(98)00060-9.

24.Stepanovic S, Vukovic D, Dakic I, Savic B, Svabic-Vlahovic M. A modified microtiter-plate test for quantification of staphylococcal biofilm formation. J Microbiol Methods. 2000; 40(2):175-9.

25. Auger S, Ramarao N, Faille C, Fouet A, Aymerich S, Gohar M. Biofilm formation and cell surface properties among pathogenic and nonpathogenic strains of the Bacillus cereus group. Appl Environ Microbiol. 2009; 75(20):6616-8. doi: 10.1128/AEM.00155-09.

26. Chmielewski R.A.N, Frank J.F. Biofilm formation and control in food processing facilities. Compr Rev Food Sci Food Saf. 2003; 2(1):22-32. doi: 10.1111/j.1541-4337.2003.tb00012.x.

27. Pagedar A, Singh J. Influence of physiological cell stages on biofilm formation by Bacillus cereus of dairy origin. Inter Dairy J. 2012; 23(1):30-35.

28. Helgason E, Okstad OA, Caugant DA, Johansen HA, Fouet A, Mock M, et al. Bacillus anthracis, Bacillus cereus and Bacillus thuringiensisOne species on the basis of genetic evidence. Appl Environ Microbiol. 66(6):2627-30.

29. García K, Ibarra JE, Bravo A, Díaz J, Gutiérrez D, Torres PV, et al. Variability of Bacillus thuringiensis strains by ERIC-PCR and biofilm formation. Curr Microbiol. 2015; 70(1):10-8. doi: 10.1007/s00284014-0675-8.

30. Bravo A, Likitvivatanavong S, Gill SS, Soberón M. Bacillus thuringiensis: a story of a successful bioinsecticide. Insect Biochem Mol Biol. 2011; 41(7):423-31. doi: 10.1016/j.ibmb.2011.02.006.

31. Rönner U, Husmark U, Henriksson A. Adhesion of Bacillus spores in relation to hydrophobicity. J Appl Bacteriol. 1990; 69(4):550-6.

32. Vanegas M, Correa N, Morales A, Martínez A, Rúgeles L, Jiménez F. Resistencia a antibióticos de bacterias aisladas de biopelículas en una planta de alimentos. Rev. MVZ Córdoba. 2009; 14(2):1677-1683.

33. Hsueh YH, Somers EB, Wong AC. Characterization of the codY gene and its influence on biofilm formation in Bacillus cereus. Arch Microbiol. 2008; 189(6):557-68. doi: 10.1007/s00203-008-0348-8.

34. Hsueh YH, Somers EB, Lereclus D, Wong AC. Biofilm formation by Bacillus cereus is influenced by PlcR, a pleiotropic regulator. Appl Environ Microbiol. 2006; 72(7):5089-92 doi:10.1128/AEM.00573-06.

35. Sonenshein A. L. CodY, a global regulator of stationary phase and virulence in gram-positive bacteria. Curr Opin Microbiol. 2005; 8(2):203- 7. doi:10.1016/j.mib.2005.01.001.

36. Verplaetse E, Slamti, Gohar M, Lereclus D. Cell differentiation in a Bacillus thuringiensis population during planktonic growth, biofilm formation, and host infection. mBio. 2015; 6(3):e00138-15. doi:10.1128/mBio.00138-15.

37. Bishop A. H, Rachwal P. A, Vaid A. Identification of Genes Required by Bacillus thuringiensis for Survival in Soil by Transposon-Direct Insertion Site Sequencing. Curr Microbiol. 2014; 68(4):477-85. doi 10.1007/s00284-013-0502-7.

38. Simões LC, Simões M, Vieira MJ. Adhesion and biofilm formation on polystyrene by drinking water-isolated bacteria. Antonie Van Leeuwenhoek. 2010; 98(3):317-29. doi: 10.1007/s10482-010-94442.

39. Thomas WE, Trintchina E, Forero M, Vogel V, Sokurenko EV. Bacterial adhesion to target cells enhanced by shear force. Cell. 2002; 109(7):921-23. 